\title{
NUTRIÇÃO MINERAL DE HORTALIÇAS. XX. Absorção de Macro e Micronutrientes Pela Ervilha (Pisum sativum L.)
}

\author{
M. A. S. Santos *: \\ H. P. HAAG *** \\ J. R. SARRUGE ***
}

\section{RESUMO}

\begin{abstract}
O presente trabalho teve o objetivo de estudar alguns aspectos da nutrição da ervilha, nas variedades Okaw e Asgrow 40 no que concerne a extração dos macro e micronutrientes durante o desenvolvimento das plantas.

Sementes de ervilha de ambas variedades foram postas a germinação em sílica. Uma vez germinados as plantulas foram irrigadas com soluçāo nutritiva completa até ao final do ciclo. Periodicamente, de $10 \mathrm{em} 10$ dias até aos 90 dias plantas foram coletadas, mensuradas em altura, determinado 0 peso da matéria fresca e seca, analisadas para os macro e micronutrientes.
\end{abstract}

A variedade Okaw apresentou um desenvolvimento e extração maior de nutrientes, do que a variedade Asgrow 40. A variedade Okaw apresenta maior exportação de nutriente.

\section{INTRODUÇÃO}

As variedades são agrupadas em: ervilha para debulhar e ervilha de vagens comestíveis. Em ambos os grupos são encontradas variedades de pequeno porte $(25 \mathrm{a} 50 \mathrm{~cm}$ ), de porte médio (50 a $100 \mathrm{~cm}$ ) e de porte elevado (mais de $100 \mathrm{~cm}$ ). Dentre as do grupo de vagens comestíveis, destaca-se a Torta-de-Flor-Roxa (Okaw), de porte elevado, muito rústica, que no Estado de São Paulo tem apresentado os melhores resultados, segundo BERNARDI (1961). Possue maturação escalonada e o seu cultivo se restringe a pequenas áreas. O seu mercado é como vagens verdes e grãos secos.

Nas variedades para debulhar, é onde se apoiam as indústrias

* Parte da Dissertação apresentada pelo primeiro autor, para obtenção do título de MESTRE pela Universidade de S. Paulo - Entregue para publicação 27/12/72.

** Estação Experimental de Jatinã (IPA). Belém de São Francisco — Pe. Bolsista do CNPq.

*** Departamento de Química, E.S.A. "Luiz de Queiroz" - U.S.P. 
de enlatados, a variedade Asgrow 40 de porte médio, é uma das que tem se destacado pela produtividade e uniformidade de maturação.

o Rio Grande do Sul é o maior produtor de ervilha do Brasil. A cultura ocupa uma área de cêrca de $4.800 \mathrm{ha}$, em duas regiões de produções distintas: Sudeste e Sudoeste do Estado. A produção do ano agricola de 1966 foi de cêrca de $4.000 .000 \mathrm{~kg}$ de grãos verdes (OLIVEIRA et alii., 1968).

Trata-se de uma cultura que tende a se expandir tanto no Estado do Rio Grande do Sul, como também em outros Estados de clima favorável. Entretanto, são excassos em nosso meio os experimentos com esta leguminosa no que se refere a sua nutrição, base necessária para os programas de adubações.

O objetivo do presente trabalho é:

Avaliar as quantidades de macro e micronutrientes extraídas por duas variedades de ervilha, durante o desenvolvimento da cultura.

\section{MATERIAL E MÉTODOS}

Em vasos de barro pintado internamente com Neutrol 45 contendo aproximadamente $7 \mathrm{~kg}$ de sílica lavada, foram semeadas cerca de 20 sementes de ambas as variedades (Okaw e Asgrow 40) por vaso, mantendo-se um teor de umidade adequado mediante adições periódicas de água.

A germinação deu-se 6 dias após, e passou-se a fornecer os nutrientes às plântulas 2 a 3 vezes ao dia com solução nutritiva completa *, diluída $1: 2$. Passados 5 dias, a solução foi trocada por uma de maior concentração (1:1) e aos 10 dias passou-se a usar solução nutritiva sem diluição. Nesta ocasião procedeu-se a coleta da primeira amostragem.

Cada 5 dias a solução nutritiva era renovada, sendo que durante este período o volume do frasco coletor (1 litro) era completado com água destilada.

As amostras eram coletadas ao acaso a intervalos de 10 dias, com um número de plantas nunca inferior a 6 . Por ocasião da coleta as plantas eram medidas em altura $(\mathrm{cm})$ a partir do colo até o ápice, em seguida divididas em caule, folhas, flores e vagens. Pesadas $(\mathrm{g})$, lavadas convenientemente com água desmineralizada e pos-

* $\mathrm{KH}_{2} \mathrm{PO}_{4} \mathrm{M}-1 \mathrm{ml} / 1 ; \mathrm{KNO}_{3} \mathrm{M}-5 \mathrm{ml} / 1 ; \mathrm{Ca}\left(\mathrm{NO}_{3}\right)_{2} \mathrm{M}-5 \mathrm{ml} / 1 ; \mathrm{MgSO}_{4} \mathrm{M}-2 \mathrm{ml} / 1$ micronutrientes $-1 \mathrm{ml} / 1$; FeERTA $-1 \mathrm{ml} / 1$. 
tas a secar em estufa de circulação contínua de ar a $80^{\circ} \mathrm{C}$. Determinado o peso da matéria seca $(\mathrm{g})$ e moída em moinho Willy com peneira n. 20 , sendo posteriormente analisados quimicamente.

$\mathrm{O}$ nitrogênio foi determinado pelo método Kjedhal semi micro descrito por MALAVOLTA (1957).

No extrato nítrico-perclórico foram seguidas as recomendações de LOTT et alii (1956) na dosagem do fósforo; potássio por fotometria de chama, método de SARRUGE (1971); enxôfre pelo método do sulfato de bário de CHAPMAM e PRATT (1961). O boro e o molibdênio foram determinados pelos métodos de JOHNSON e ULRICH (1959).

Cálcio, magnésio, cobre, ferro, manganês e zinco foram determinados no extrato nítrico-perclórico por espectrofotometria de absorção atômica, PERKIN-ELMER (1966).

\section{RESULTADOS E DISCUSSÃo}

\section{Desenvolvimento das plantas. Variedade Okaw}

As tabelas 1 e 2 contem os pesos de matéria verde e seca (g) e das alturas $(\mathrm{cm})$ da variedade Okaw em diferentes idades.

Com os dados relativos às produções totais, contruiu-se a Figura 1 para melhor visualizar este desenvolvimento.

A Figura 1, no que concerne a matéria verde mostra um aumento pequeno nos primeiros 20 dias, para depois crescer vertiginosamente até os 73 dias, permanecendo constante até o $83 .^{\circ}$ dia, para depois crescer até a última amostragem. A paralização do crescimento entre o $73 .^{\circ}$ e $830^{\circ}$ dia se deve talvez a queda das folhas e a perda de umidade pelas plantas que vão envelhecendo; e o aumento seguinte se deve a produção de vagens. Com relação a matéria seca observa-se que o crescimento é mais ou menos contínuo até o 53.0 dias, quando cresce bruscamente até os 73 dias, decrescendo um pouco no $83 .^{\circ}$ dia quando volta a crescer no $93 .^{\circ}$ dia, atingindo o valor máximo. O decréscimo da matéria seca observado no $83 .^{\circ}$ dia se deve a queda das folhas que foi abundante neste período, e o aumento seguinte a produção de vagens e folhas novas.

Atribuindo-se o valor $100 \%$ à produção de matéria seca correspondente à amostragem feita aos 93 dias após a germinação e exprimindo-se as produções anteriores em percentagens desta, obtemse as produções nos dias $13,23,33,43,53,63,73$ e 83 dias após, a germinação foram respectivamente $0,4 \%, 1,5 \%, 5,8 \%, 11,2 \%, 19,5 \%$, $40,9 \%, 72,1 \%$ e $68,1 \%$. 
TABELA 1 - Altura ( $\mathrm{cm}$ ) e peso da matéria verde das plantas $(\mathrm{g})$ nas diversas amostragens. Média de 25 plantas.

\begin{tabular}{ccccccc}
\hline \multirow{2}{*}{$\begin{array}{c}\text { Dias } \\
\text { após a } \\
\text { germinação }\end{array}$} & $\begin{array}{c}\text { Altura } \\
(\mathrm{cm})\end{array}$ & \multicolumn{2}{c}{ Peso médio dos órgãos das plantas (g) } & total \\
\cline { 6 - 7 } \cline { 5 - 6 } & & caule & folha & flor & vagem & \\
\hline 13 & 10 & 1,08 & - & - & - & 1,08 \\
23 & 30 & 1,40 & 1,94 & - & - & 3,34 \\
33 & 60 & 7,18 & 7,56 & - & - & 14,74 \\
43 & 100 & 13,75 & 7,64 & - & - & 21,39 \\
53 & 120 & 23,55 & 18,48 & 1,17 & - & 43,18 \\
63 & 180 & 61,67 & 42,33 & - & 10,50 & 114,50 \\
73 & 200 & 61,50 & 42,67 & - & 53,90 & 158,07 \\
83 & 200 & 58,83 & 36,33 & - & 63,50 & 158,66 \\
93 & 200 & 60,33 & 19,42 & - & 93,15 & 172,90 \\
\hline
\end{tabular}

TABELA 2 - Peso da matéria seca ( $\mathrm{g}$ ) das plantas nas diversas amostragens. Média de 25 plantas.

\begin{tabular}{cccccc}
\hline \multirow{2}{*}{$\begin{array}{c}\text { Dias } \\
\text { após a } \\
\text { germinação }\end{array}$} & \multicolumn{3}{c}{ Peso médio dos órgãos das plantas $(\mathrm{g})$} & \\
\cline { 2 - 5 } & caule & folha & flor & vagem & \\
\hline 13 & 0,13 & - & - & - & 0,13 \\
23 & 0,18 & 0,35 & - & - &.. \\
33 & 0,93 & 1,03 & - & - & 1,53 \\
43 & 1,80 & 1,92 & - & - & 3,72 \\
53 & 3,16 & 2,90 & 0,13 & - & 6,19 \\
63 & 10,58 & 4,33 & - & 1,40 & 16,31 \\
73 & 11,87 & 5,43 & - & 6,68 & 23,90 \\
83 & 10,67 & 4,48 & - & 7,50 & 22,65 \\
93 & 15,07 & 6,30 & - & 12,00 & 33,27 \\
\hline
\end{tabular}




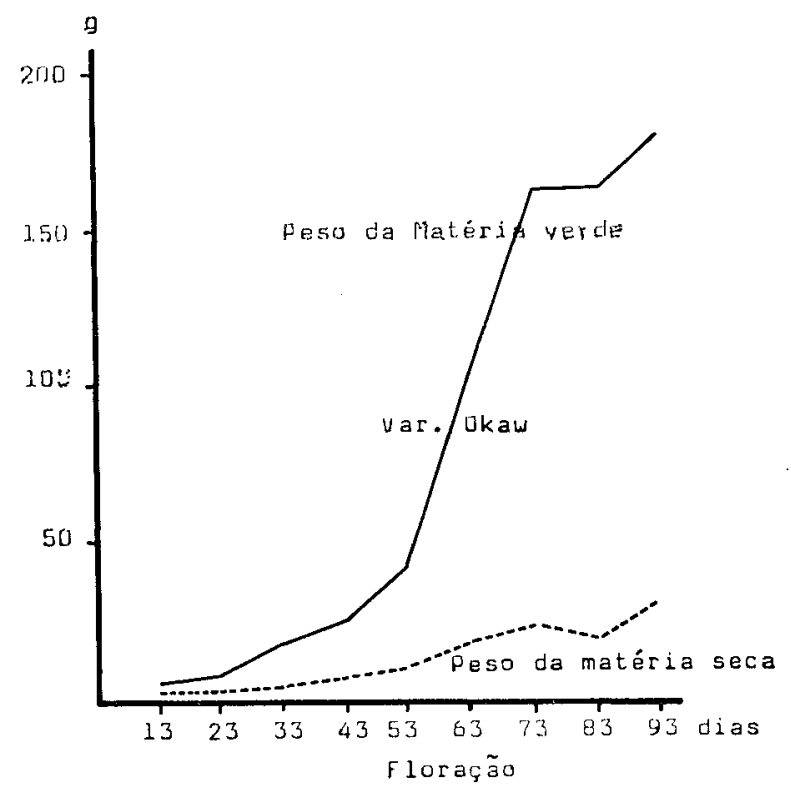

FIG. 1 - Peso da matéria verde e seca (g) total da planta. Média de 25 plantas.

A produção da matéria verde dos caules cresceu até o $63 .^{\circ}$ dia quando permaneceu constante. $\mathrm{O}$ peso de matéria seca elevou-se até o $73 .^{\circ}$ dia, quando sofreu uma pequena redução no $83 .^{\circ}$ dia, para voltar a crescer entre esta e a última amostragem. Considerando-se como $100 \%$ a produção de matéria seca aos 93 dias, tem-se as seguintes produções percentuais em relação àquela para amostragens anteriores, $1,2 \%, 6,2 \%, 11,9 \%, 21,0 \%, 70,2 \%, 78,8 \%$ e $70,8 \%$,respectivamente.

Observou-se nas Tabelas 1 e 2, com referência às folhas, que o peso de matéria verde aumentou até o $73 .^{\circ}$ dia, para decrescer nas amostragens seguintes, ao passo que o peso de matéria seca cresceu sempre, com excessão do valor observado no $83 .^{\circ}$ dia. Considerando como $10 \%$ a produção de matéria seca para o $93 .{ }^{\circ}$ dia, temos para as amostragens anteriores em produções percentuais, $16,6 \%, 30,9 \%$, $46,8 \%, 70,0 \%, 87,6 \%$ e $72,2 \%$.

Os pesos de matéria verde e seca das flores foram mais elevados aos 53 dias após a germinação devido a floração intensa.

\section{Variedade Asgrow 40}

Nas tabelas 3 e 4 estão contidos os pesos médios de matéria verde e seca $(\mathrm{g})$ e as alturas médias $(\mathrm{cm})$ nas diferentes amostragens. 
TABELA 3 - Altura ( $\mathrm{cm}$ ) e peso da matéria verde $(\mathrm{g})$ em função do desenvolvimento. Média de 30 plantas.

\begin{tabular}{|c|c|c|c|c|c|c|}
\hline \multirow{2}{*}{$\begin{array}{l}\text { Dias } \\
\text { após a } \\
\text { germinação }\end{array}$} & \multirow{2}{*}{$\begin{array}{c}\text { Altura } \\
(\mathrm{cm})\end{array}$} & \multicolumn{4}{|c|}{ Peso da matéria verde $(\mathrm{g})$} & \multirow{2}{*}{ Total } \\
\hline & & caule & folhas & flores & vagens & \\
\hline 16 & 5 & 1,03 & - & - & - & 1,03 \\
\hline 26 & 12 & 0,90 & 2,22 & - & - & 3,12 \\
\hline 36 & 22 & 3,13 & 5,77 & - & - & 8,90 \\
\hline 46 & 35 & 9,50 & 13,78 & - & - & 23,28 \\
\hline 56 & 45 & 17,33 & 19,25 & 1,04 & - & 37,62 \\
\hline 66 & 65 & 9,40 & 23,95 & - & 3,20 & 36,55 \\
\hline 76 & 70 & 20,00 & 13,33 & - & 3,67 & 37,00 \\
\hline 86 & 80 & 15,46 & 9,07 & - & 6,21 & 30,74 \\
\hline 96 & 90 & 15,29 & 10,56 & - & 4,52 & 30,37 \\
\hline
\end{tabular}

TABELA 4 - Peso da matéria seca das plantas ( $\mathrm{g}$ ) em função do desenvolvimento. Média de 30 plantas.

\begin{tabular}{cccccc}
\hline \multirow{2}{*}{$\begin{array}{c}\text { Dias } \\
\text { após a } \\
\text { germinação }\end{array}$} & caule & folhas & flores & vagens & Total \\
\cline { 3 - 5 } & 0,15 & - & - & - & 0,15 \\
16 & 0,08 & 0,23 & - & - & 0,31 \\
26 & 0,30 & 0,78 & - & - & 1,08 \\
36 & 0,90 & 2,00 & - & - & 2,90 \\
46 & 1,97 & 0,59 & 0,12 & - & 4,68 \\
56 & 2,37 & 4,79 & - & 0,26 & 7,42 \\
66 & 3,74 & 3,10 & - & 0,66 & 7,50 \\
76 & 2,74 & 2,58 & - & 0,71 & 6,03 \\
86 & 3,63 & 3,46 & - & 0,93 & 8,02 \\
96 & & & & & \\
\hline
\end{tabular}




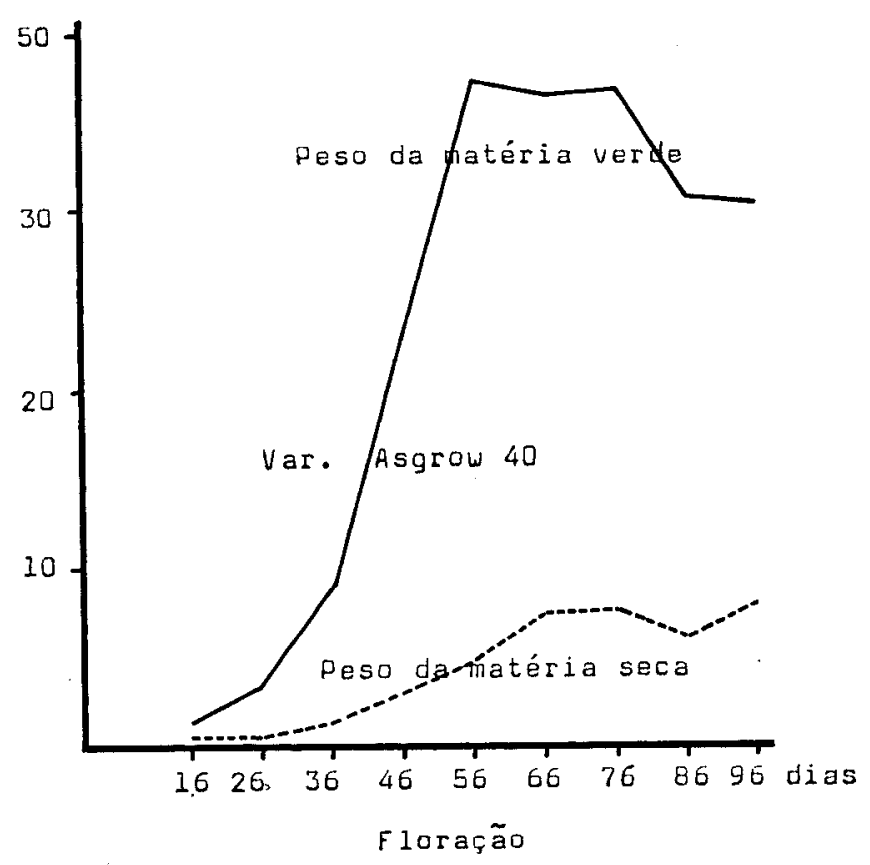

FIG. 2 - Peso da matéria verde e seca total da planta. Média de 30 plantas.

Para melhor visualizar o desenvolvimento das plantas, com os dados de produções totais construiu-se a Figura 2.

Observa-se na Figura 2, no que concerne a matéria verde um crescimento vertical até o $56 .^{\circ}$ dia, quando o crescimento paralizou-se até o 76..$^{\circ}$ dia então decresceu até a última amostragem. A explicação para esta paralização do crescimento seguida do decréscimo na matéria verde, se deve a perda de umidade pelas plantas e queda das folhas, que foi intensa neste período. Com referência a matéria seca, observa-se que o crescimenot foi mínimo nos primeiros 10 dias, para depois crescer verticalmente até os 66 dias quando o crescimento estabilizou-se, decresceu no $86 .^{\circ}$ dia devido talvez a queda das folhas e cresceu na última amostragem, quando a produção de folhas novas e vagens propiciou o máximo de matéria seca.

Este decréscimo na matéria seca aos 80 dias do ciclo da ervilha foi verificado para as duas variedades, parecendo ser uma característica da espécie.

Atribuindo-se o valor $100 \%$ à produção de matéria seca correspondente a amostra colhida aos 96 dias após a germinação, e exprimindo-se as produções anteriores em percentagens desta, obtem-se 
para as produções das amostragens dos dias $16,26,36,46,56,66$, 76 e 86 dias após a germinação os seguintes valores, respectivamente: $1,9 \%, 3,9 \%, 13,5 \%, 36,1 \%, 58,3 \%, 92,5 \%$ e $75,2 \%$.

A produção da matéria verde e seca dos caules cresceu até o 76..$^{\circ}$ dia após a germinação quando atingiu o valor máximo, daí então um decréscimo para as 2 últimas amostragens. Considerando-se como $100 \%$ a produção de matéria seca nos 76 dias e exprimindo as produções das amostragens anteriores em percentagem desta, temos para os $16,26,36,46,56$ e 66 dias, respectivamente $1,9 \%, 2,1 \%, 8,0 \%$, $24,1 \%, 52,7 \%$ e $63,4 \%$.

Para as folhas, observa-se nas Tabelas 3 e 4, que o máximo de produção ocorreu aos 66 dias, seguindo-se um decréscimo para as duas amostragens seguintes, para posteriormente na última amostragem haver um acréscimo. Considerando como $100 \%$ o peso de matéria seca no $66^{\circ}$ dia, e exprimindo as produções anteriores em percentagem desta, obtem-se para os $26,36,46$ e 56 dias, respectivamente, $4,8 \%, 16,3 \%, 41,7 \%$, e $54,1 \%$.

As produções de matéria verde e seca das flores foi maior no $56 .^{\circ}$ dia, devido a intensidade de floração.

As produções de matéria verde e seca das vagens aumentaram continuamente do $66 .^{\circ}$ até o $96 .^{\circ}$ dia.

O crescimento da matéria verde e seca apresentou-se distintamente para as duas variedades em questão. A variedade Ikaw apresentou crescimento continuo durante todo ciclo estudado e na última amostragem, 93. ${ }^{\circ}$ dia, foi que observou-se o máximo de produção; a variedade Asgrow 40, no entanto, a produção de matéria verde alcançou o máximo no meio do ciclo, cerca de 56 dias, ao passo que a produção de matéria seca foi máxima no $96 .^{\circ}$ dia.

A matéria verde e seca total máxima, foi maior para a variedade Okaw devido ser esta de porte elevado, a formação do material vegetal é maior que a variedade Asgrow 40 de porte médio.

$O$ crescimento da matéria verde e seca da variedade Okaw foi, em termos gerais, semelhante ao observado por HAAG e HOMA (1968) e (1969) para a beringela e cenoura.

A produção de matéria verde e seca pela variedade Asgrw 40 foi de um modo geral, semelhante ao observado por COBRA NETO (1967) para o feijoeiro, e coincidentemente o maior valor da matéria verde foi aos 56 dias após a germinação. 


\section{Concentração dos macro e micronutrientes nos órgãos das plantas}

\section{Variedade Okaw}

As análises químicas das matérias secas dos órgãos das plantas permitiram a elaboração das Tabelas 5 e 6, e através delas torna-se possível fazer algumas observações.

Entre os órgãos vegetativos, as folhas apresentaram teores mais elevados dos macronutrientes nitrogênio, cálcio, magnésio e enxôfre, e dos micronutrientes boro, ferro, mangansê e zinco durante todo o ciclo vegetativo. Os teores em miligrama do fósforo nas folhas foram maiores nos primeiros 53 dias, quando devido a produção de matéria seca nos caules provocou um grande aumento do teor de fósforo. Os caules mostraram-se muito ricos em potássio, estes teores aumentaram à medida que as plantas envelheciam.

Dos micronutrientes, observa-se que os teores de molibdênio foram maiores nos caules; nas folhas encontrou-se os teores mais baixos.

Com relação aos órgãos reprodutivos, deve-se ressaltar o elevado teor, em percentagens, do fósforo; maior nas flores que nas vagens.

Os teores percentuais de nitrogênio, fósforo e potássio tenderam a decrescer com a idade da planta. Para o cálcio, ocorreu um decréscimo nos caules e um aumento nas folhas à medida que a planta envelhecia, fato idêntico observado para o magnésio. $O$ teor de enxofre decresceu até a penúltima amostragem, e na seguinte apresentou os valores mais elevados. Os teores em partes por milhão de cobre, ferro e molibdênio decresciam à medida que a planta envelhecia. $\mathrm{O}$ boro de uma maneira geral, cresceu com a idade das plantas. Os teores de manganês e zinco talvez não reflitam a verdadeira necessidaded a planta devido a pulverizações periódicas feitas com Dithame-M45, fungicida que possue no princípio ativo $16 \%$ de manganês e $2 \%$ de zinco. Os teores dos macronutrientes nas plantas apresentaram-se na seguinte ordem decrescente: nitrogênio, potássio, cálcio, enxofre, fósforo e magnésio; para os micronutrientes, a ordem foi ferro, boro, manganês, zinco, cobre e molibdênio.

\section{Variedade Asgrow 40}

As análises químicas da matéria seca dos órgãos das plantas permitiu que as tabelas 5 e 6 fossem elaboradas, e algumas observações foram feitas.

As folhas apresentaram teores percentuais mais elevados dos 


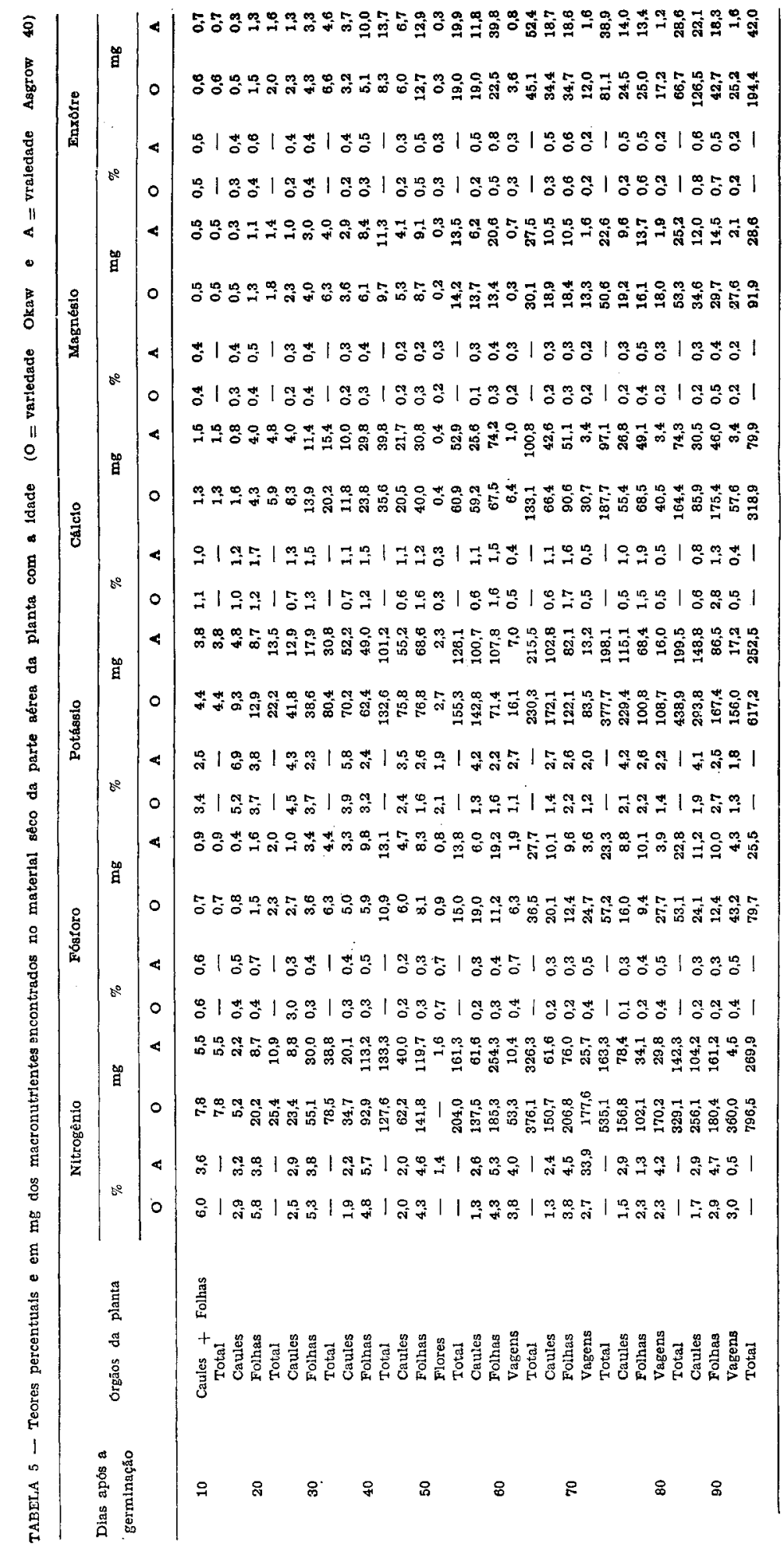




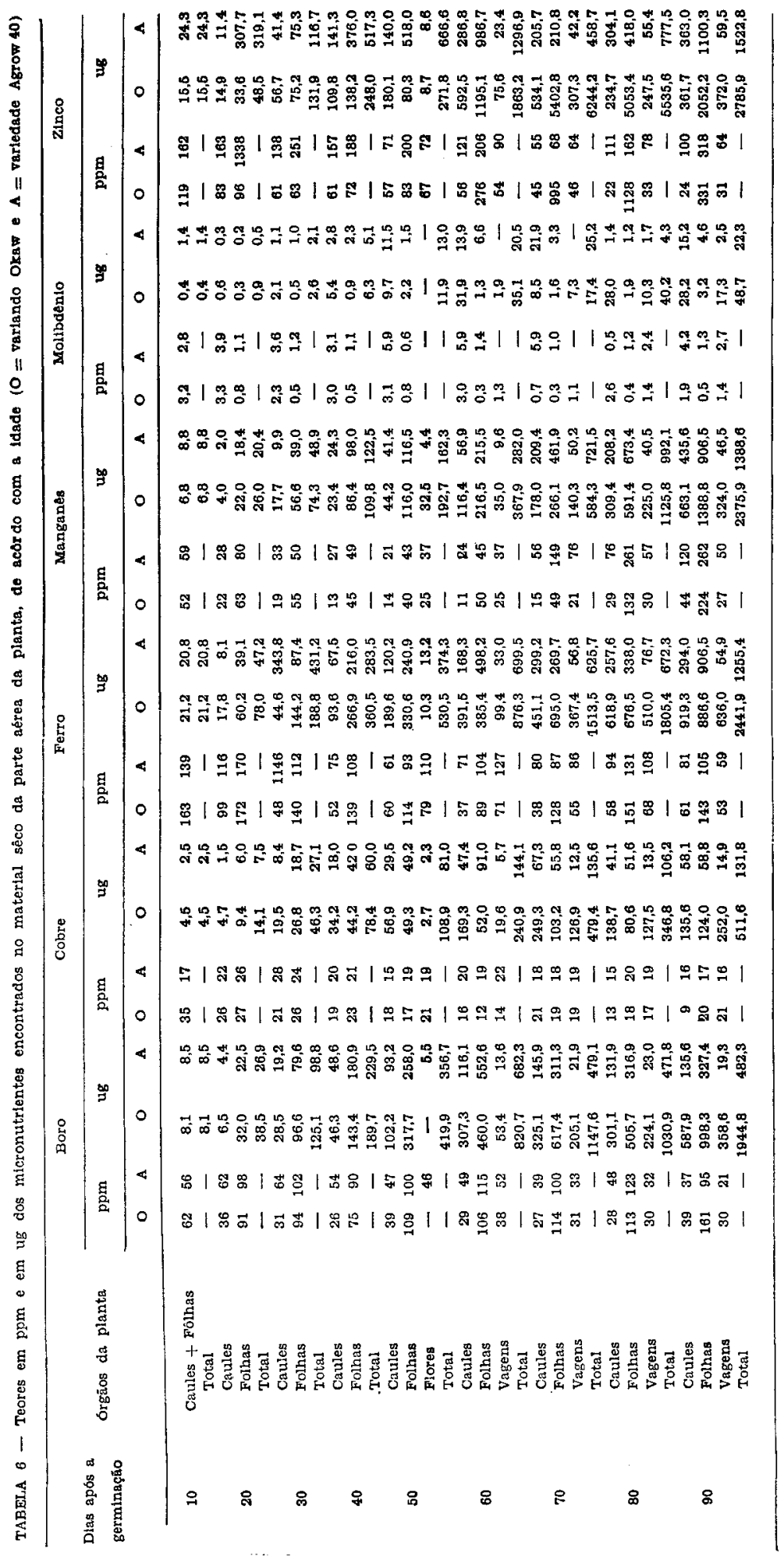


macronutrientes nitrogênio, fósforo, cálcio, magnésio e enxofre que os caules. Os teores de potássio em caules foram superiores aos das folhas; dos órgãos reprodutivos, as flores eram as mais ricas em fósforo.

Os micronutrientes apresentaram teores em partes por milhão mais elevados nas folhas, excessão feita ao molibdênio que apresentou teores mais elevados nos caules.

Enquanto que os teores em percentagem dos macronutrientes decrescia à medida que a planta envelhecia, observou-se um aumento crescente, devido a formação de matéria seca, dos teores em $\mathrm{mg}$ dos mesmos. De um modo geral as folhas acumularam as maiores quantidades dos nutrientes em questão.

Os teores dos macronutrientes nas plantas obedeceram a seguinte ordem decrescente: nitrogênio e potássio, cálcio, fósforo, enxofre e magnésio, respectivamente em percentagem.

Os teores em partes por milhão dos micronutrientes, decresceram à medida que a planta envelhecia, excessão feita a boro, manganês e zinco que cresceram. O motivo do aumento dos teores de manganês e zinco, se deve talvez às pulverizações com Dithame M45. Os teores em micrograma dos nutrientes elevaram-se sempre.

Os micronutrientes apresentaram teores mais elevados nas folhas, excessão feita ao molibdênio que concentrou-se nos caules.

Os teores dos micronutrientes nas plantas, apresentaram-se na seguinte ordem decrescente: ferro, zinco, boro, manganês, cobre e molibdênio.

Comparandos-e os teores em percentagem para os macronutrientes nas duas variedades, observou-se que a Asgrow 40, com excessão para o nitrogênio, apresentou teores mais elevados que a Okaw; no entanto, os teores em miligrama da segunda foram superiores devido ser variedade de porte elevado, e haver maior produção de matéria seca.

Em se tratando dos micronutrientes, observou-se que sempre as quantidades em micrograma foram superiores para a variedade Okaw, devido ao porte elevado desta; relação esta não observada quando os nutrientes foram expressos em partes por milhão.

Os valores obtidos neste trabalho, discordaram pouco daquele verificado para os nutrientes nitrogênio, fósforo, potássio, cálcio, magnésio, manganês e ferro, na variedade Alaska por McHARGUE (1923a).

Para o fósforo, o teor na fôlha no período compreendido entre 
os 40 e 80 dias observados por THEMBLAY e BAUR (1952), está um pouco aquém do encontrado no presente trabalho. A variedade Asgrow 40 apresentou teor mais elevado nas folhas em todo o período; ao passo que a variedade Okaw tendeu a se igualar aos teores citados por estes autores.

Os valores percentuais encontrados para nitrogênio, fósforo e potássio na variedade Okaw, são idênticos aos citados por Heenney et alii., (1960). Para a variedade Asgrow 40, no entanto, os valores, com excessão do potássio que foi inferior, foram sempre superior aqueles encontrados pelos autores citados.

Analisando folhas na época do florescimento em um experimento de campo com três variedades, MACLEAN e BYERIS (1968) encontraram valores que diferem muito pouco dos observados neste trabalho. Os autores encontraram 4,6\% de nitrogênio; 0,4 de fósforo; $2,2 \%$ de potássio ; $1,0 \%$ de cálcio e $0,3 \%$ de magnésio. Para os micronutrientes, $110 \mathrm{ppm}$ de ferro; $73 \mathrm{ppm}$ de mangansê; $21 \mathrm{ppm}$ de boro; 0,50 ppm de molibdênio e $33 \mathrm{ppm}$ de zinco, respectivamente. Como bem se pode observar, os dados encontrados neste trabalho diferem apenas para o fósforo e manganês que foram inferiores e boro e molibdênio muito mais elevados.

Devido talvez ao acúmulo de zinco resultante das pulverizações com Dithane M-45, os valores encontrados pelos autores indicam o nível adequado de zinco (33 ppm).

\section{Quantidades dos nutrientes encontrados nos órgãos das plantas}

Com os dados referentes oa peso de matéria seca (g) e os teores dos nutrientes nos diversos órgãos das plantas para as duas variedades de ervilha, contém em média $100.000 \mathrm{pl}$./ha para a variedade Okaw e $200.000 \mathrm{pl} /$ ha para a variedade Asgrow 40, segundo BERNARDI (1961), elaborou-se as tabelas 7 e 8 . As tabelas contém as quantidades de nutrientes extraídos pelos órgãos das plantas, como também os teores totais, em $\mathrm{kg} / \mathrm{ha}$ para os macronutrientes e em $\mathrm{g} / \mathrm{ha}$ para os micronutrientes.

\section{Extração dos macronutrientes}

As quantidades totais de nitrogênio absorvido pelas variedades Okaw e Asgrow 40, foi idêntica nos primeiros 30 dias, figura 3 (a). Dai então a quantidade absorvida pela Asgrow 40 sofre um aumento brusco até atingir o máximo aos 60 dias, para decrescer bruscamente até o $800^{\circ}$ dia e voltar a crescer na última amostragem; ao passo que a absorção verificada pela variedade Okaw, foi contínua até os 


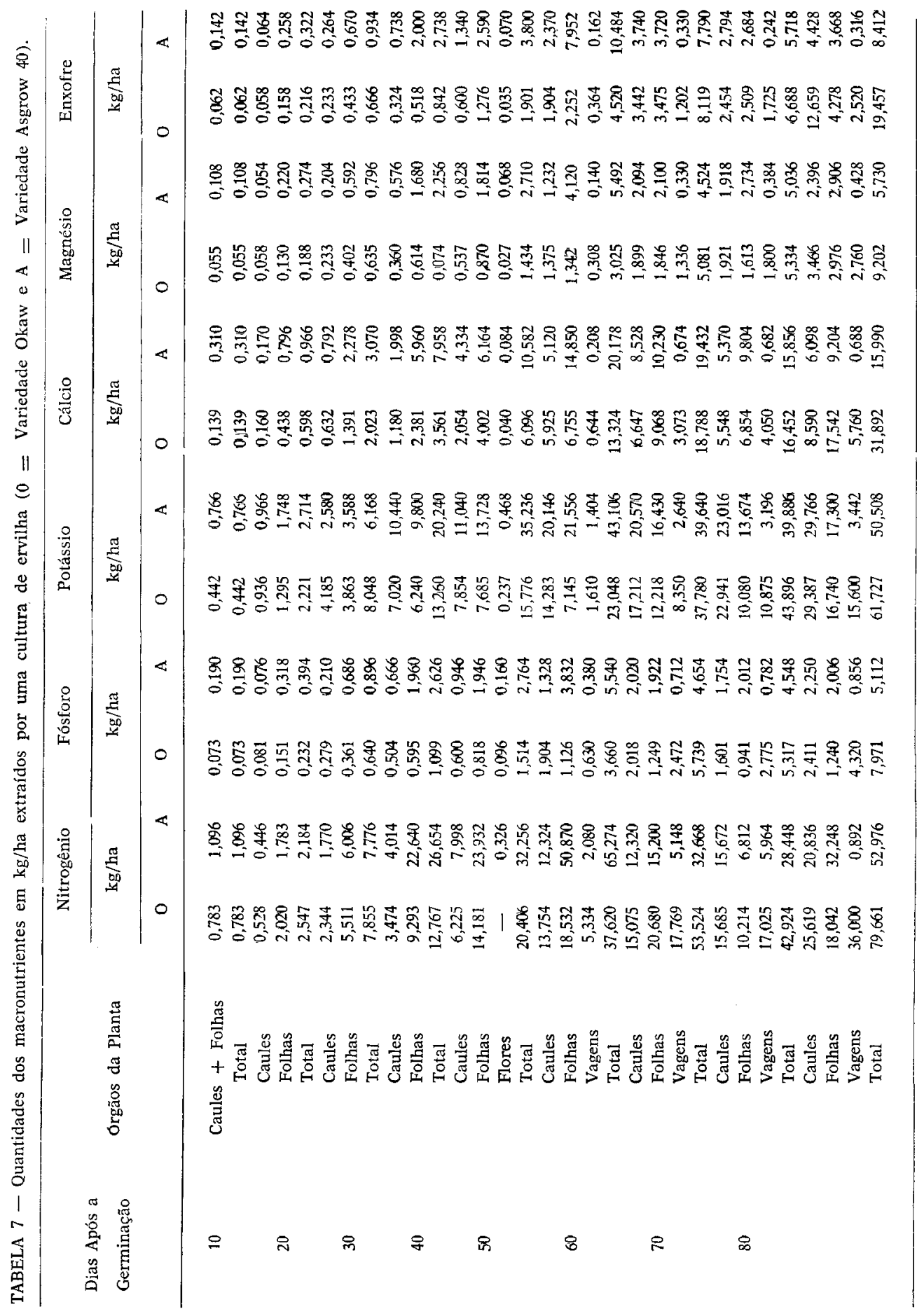




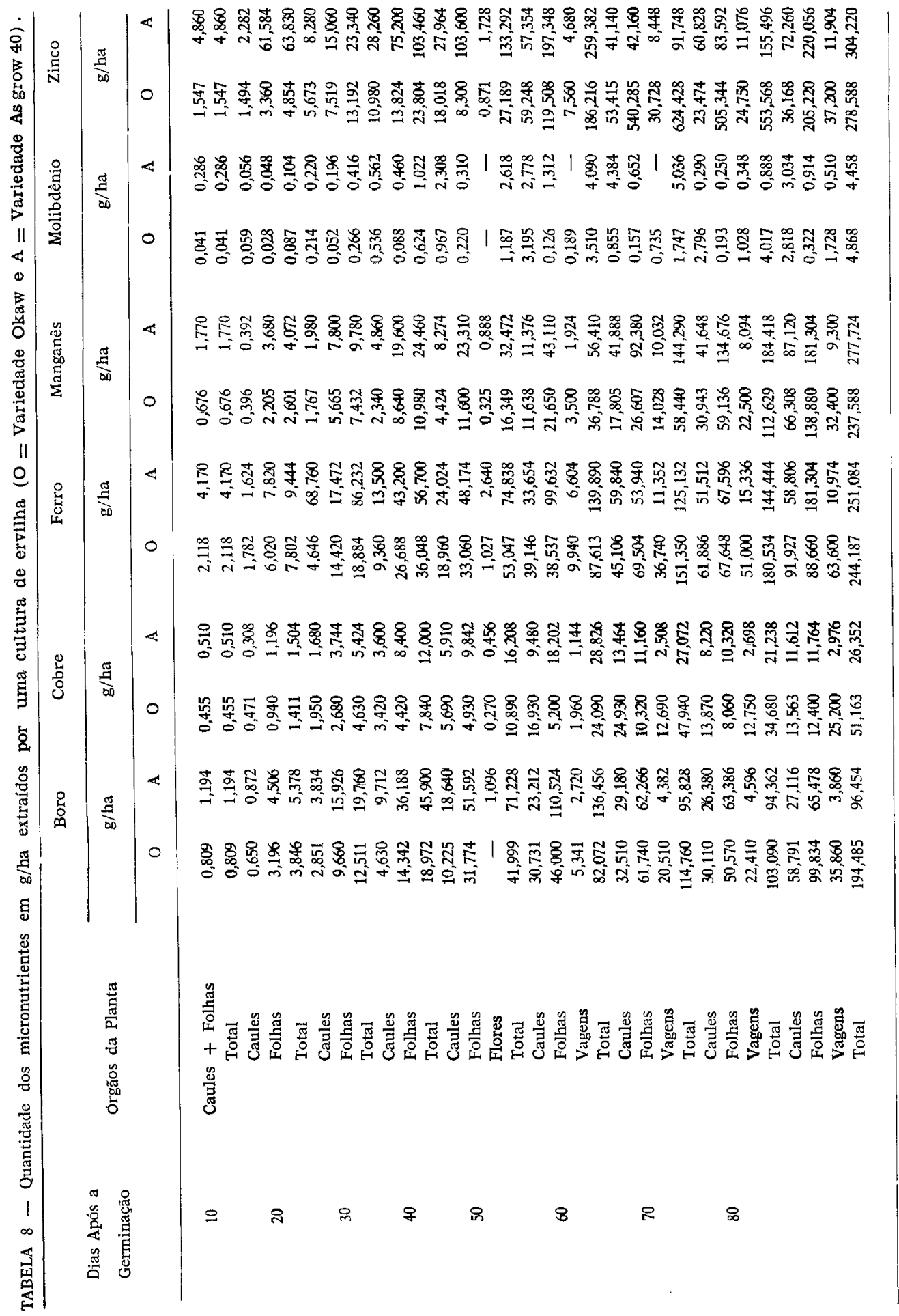


70 dias, seguidap or um decréscimo no $80 .^{\circ}$ dia e voltar a crescer e atingir o valor máximo nos 90 dias.

Para as duas variedades, o decréscimo na absorção do nitrogênio aos 80 dias se deve talvez a queda das fôlhas velhos, abundante neste período e a translocação do nutriente dos caules e folhas para os frutos; e o aumento no $90^{\circ}$ dia a produção de novas folhas e vaegns. As quantidades de nitrogênio contidas nas vagens da variedade Okaw, foram superiores às observadas para a variedade Asgrow 40.

Observa-se que as duas variedades estudadas apresentam épocas preferenciais distintas de absorção do nutriente. Enquanto a variedade Asgrow 40 aos 60 dias absorve a quantidade máxima de nitrogênio, a Okaw só no fim do ciclo é que verificou-se este fato. Tomando-se a quantidade de nitrogênio absorvido aos 60 dias como máxima e somando-se as quantidades deste nutriente nos frutos nas três últimas amostragens para a variedade Asgrow 40, encontra-se um valor de aproximadamente $78 \mathrm{~kg} / \mathrm{ha}$ que difere muito pouco dos $80 \mathrm{~kg} / \mathrm{ha}$ absorvidos pela variedade Okaw.

A extração do fósforo, figura 3 (B), também apresentou, para as duas variedades, épocas preferenciais. A variedade Asgrow 40, extraiu o nutriente continuamente nos primeiros 30 dias, seguido de um aumento brusco até os 40 dias, quando houve uma estabilização no $500^{\circ}$ dia para voltar crescer e atingir o máximo no $60^{\circ}$ dia. Houve um decréscimo no $800^{\circ}$ dia, seguido de um aumento na última amostragem. Com a variedade okaw, o aumento na absorção nos primeiros 30 dias do ciclo da planta foi idêntico ao da Asgrow 40, porém em menores proporções. Houve um aumento continuo até 70 dias, seguido de um decréscimo na absorção no $80 .^{\circ}$ dia, para voltar a crescer a atingir o máximo aos 90 dias.

0 decréscimo na quantidade do fósforo contido nos órgãos vegetativos aos 80 dias para as duas variedades, se deve talvés à queda das folhas velhas e a mobilização do fósforo dos órgãos vegetativos para as vagens; e o aumento na último amostragem, a pradução de folhas novas e vagens. As vagens da variedade Okaw apresentaram quantidades de fósforo muito superiores as da variedade Asgrow 40.

Tomando-se a quantidade do fósforo absorvida na última amostragem pela variedade Okaw, $8 \mathrm{~kg} / \mathrm{ha}$, e comparando-se com 5,5 $\mathrm{kg} / \mathrm{ha}$ absorvidos aos 60 dias acrescido das quantidades encontradas nas vagens nas três últimas amostragens pela variedade Asgrow 40 , encontra-se $7,9 \mathrm{~kg} / \mathrm{ha}$, que é praticamente a mesma quantidade absorvida pela variedade anterior.

A figura 3 (C), retrata a absorção de potássio pelas duas varie- 
dades. Observa-se que nos primeiros 30 dias, as duas variedades absorveram aproximadamente a mesma quantidade de potássio, para então a Asgrow 40 sofrer um aumento brusco na absorção até o $60 .^{\circ} \mathrm{dia}$, decrescendo um pouco nos 80 dias e aumentando para atingir o máximo na última amostragem. Com a variedade Okaw, a absorção foi pequena havendo uma paralização entre os 40 e 50 dias, para daí então crescer bruscamente e atingir o máximo na última amostragem.

O decrescimo na absorção aos 80 dias na variedade Asgrow 40, se deve talvez a mobilização dos nutrientes dos órgãos vegetativos para os reprodutivos; na variedade Okaw tal fato não ocorreu devido talvez a estabilização da absorção aos 40 dias, e a quantidade reservadas. As vagens da variedade Okaw apresentaram maior quantidade de potássio que a variedade Asgrow 40, devido a maior produção da primeira.

Tomando-se o valor da última amostragem da variedade Okaw, $62 \mathrm{~kg} / \mathrm{ha}$, como valor máximo de potássio absorvido e comparandose $\mathrm{cm}$ o valor da última amostragem da variedade Asgrow 40, também máximo, $50 \mathrm{~kg} / \mathrm{ha}$, observa-se entre estes valores máximos uma diferença de $12 \mathrm{~kg} / \mathrm{ha}$, ou cerca de $20 \%$ a favor da Okaw.

Ao contrário do que ocorre para os outros macronutrientes, a absorção do cálcio é mais elevada nos primeiros 5055 dias na variedade Okaw, figura 3 (D). Após este período observou-se uma estabilização até os 80 dias, devido talvez a translocação do nutriente dos órgãos vegetativos para as flores e vagens e queda das folhas velhas.

$\mathrm{Na}$ variedade Asgrow 40, a absorção do cálcio foi semelhante, mas um pouco inferior a extração de variedade Okaw nos primeiros 50 dias, para daí alcançar o máximo aos 60 dias e descrever para estabilizar-se aos 80 dias. O decrescimo na absorção dos órgãos vegetativos se deve talvez a translocação do nutriente para as vagens e a queda das folhas velhas.

A grande quantidade de cálcio observada nas vagens da variedade Okaw, se deve a produção desta variedade ser maior do que a da Asgrow 40.

O grande aumento na absorção verificado aos 90 dias na variedade Okaw, se deve a formação de vagens e folhas novas. Tomandose o valor $32 \mathrm{~kg} / \mathrm{ha}$, o máximo absorvido neste período, e comparando-se com o valor $20 \mathrm{~kg} / \mathrm{ha}$ observado aos 60 dias pela variedade Asgrow 40, acrescentando as quantidades do cálcio nas vagens nas três últimas amostragens, obtem-se um valor de $21 \mathrm{~kg} / \mathrm{ha}$, que difere de $11 \mathrm{~kg} / \mathrm{ha}$ da variedade Okaw, ou cerca de $34 \%$ a favor desta. 
A absorção de magnésio pelas duas variedade, figura 3 (E), quase nada diferiu nos primeiros 30 dias. Deste período então, a absorção acentuou-se até o $600^{\circ}$ dia para variedade Asgrow 40, caindo um pouco aos 70 dias, para voltar a crescer até os 90 dias onde encontra-se o valor máximo. O decrescimo de absorção do nutriente na sétima amostragem se deve talvez a translocação do magnésio para as vagens em formação, e o aumento na última amostragem a formação de vagens e folhas novas. Após os 30 dias, a variedade Okaw absorveu de um modo crescente até os 70 dias, decresceu um pouco no $80 .^{\circ}$ dia para voltar a crescer na última amostragem. O motivo da menor absorção aos 80 dias se deve a translocação do magnésio das folhas e caules para os frutos, e o aumento no final, a formação de novas vagens e folhas.

As quantidades de magnésio encontradas nas vagens da variedade Okaw, foram muito superiores às da variedade Asgrow 40. Fazendo crer que se no experimento de sintomas de deficiência, tivesse sido utilizada a variedade Okaw, decerto que havia mais probabilidade de aparecerem sintomas de carência.

$\mathrm{Na}$ última amostragem encontrou-se $9,2 \mathrm{~kg} / \mathrm{ha}$, correspondente ao maior valor da absorção de magnésio pela variedade Okaw, e comparando-se com $5,7 \mathrm{~kg} / \mathrm{ha}$ correspondente ao maior valor de absorção do nutriente pela variedade Asgrow 40, encontra-se 3,5 $\mathrm{kg} / \mathrm{ha}$ como diferença, o que equivale a $38 \%$.

A absorção do enxôfre, figura $3(\mathrm{~F})$, foi similar para as duas variedades nos primeiros 20 dias, daí então a absorção verificada pela variedade Asgrow 40 foi superior até os 60 dias, seu valor máximo, decrescendo até o $800^{\circ}$ dia para depois elevar-se na última amostragem, onde ocorreu o máximo de extração.

O motivo do decréscimo na absorção aos 80 dias se deve talvez à queda de folhas velhas e a mobilização do nutriente dos órgãos vegetativos para as vagens, e o acréscimo seguinte a produção de vagens, folhas novas e matéria seca nos caules.

De modo semelhante que para o magnésio, a variedade Okaw apresentou nas suas vagens quantidade de enxôfre superior a da variedade Asgrow 40. Se no experimento de sintomas de deficiência, tivesse sido utilizada a variedade Okaw, talvez os sintomas de carência tivessem surgido, devido a sua maior extração de nutriente.

Considerando-se $19 \mathrm{~kg} / \mathrm{ha}$ como o valor máximo de enxôfre absorvido pela variedade Okaw aos 90 dias, e comparando-se com 
$10 \mathrm{~kg} / \mathrm{ha}$ observado aos 60 dias acrescida das quantidades encontradas nas vagens nas três últimas amostragens, encontra-se um valor de $11 \mathrm{~kg} / \mathrm{ha}$ para a variedade Asgrow 40 , que difere de $8 \mathrm{~kg} / \mathrm{ha}$, ou seja, $42 \%$ a favor da Okaw.

Como afirmaram MACLEAN e BYERS (1968), no Canadá, a nenecessidade de nutrientes é distinto para cada variedade. No presente estudo confirmou-se as palavras dos autores, pois a variedade Okaw mostrou-se mais exigente que a variedade Asgrow 40 nos seguintes macronutrientes: potássio, cálcio, magnésio e enxôfre. As quantidades de nitrogênio e fósforo extraídos foram semelhantes para as duas variedades. Os maiores valores de absorção para a variedade Okaw foram verificados no fim do ciclo, enquanto para a variedade Asgrow 40 as necessidades minerais eram satisfeitas aos 60 dias do ciclo da planta.

\section{Extração dos micronutrientes}

A absorção do boro figura 4 (A), pelas variedades, apresentou a Asgrow 40 como mais capaz para acumular o nutriente nos primeiros 60 dias, para daí decrescer nos 70 dias e manter-se aproximadamente constante nas duas últimas amostragens. A variedade Okaw absorveu o nutriente continuamente até o $70 .^{\circ}$ dia, decresceu esta absorção no $80 .^{\circ}$ dia e depois elevou-se na última amostragem.

O decrescimo verificado aos 80 dias, para a variedade Okaw se deve talvez.à queda das folhas velhas e a translocação do nutriente dos órgãos vegetativos para as vagens. Fato idêntico ocorreu com a variedade Asgrow 40.

Tomando-se o valor máximo, $149 \mathrm{~g} / \mathrm{ha}$, obserúado aos 90 dias para a variedade Okaw 40 aos 60 dias, acrescida das quantidades do nutriente nas variedades das três últimas amostragens, obtem-se $149 \mathrm{~g} / \mathrm{ha}$; valor que difere de $45 \mathrm{~g} / \mathrm{ha}$, ou seja, cerca de $23 \%$.

A figura 4 (B) retrata a absorção do cobre pelas variedades. Observou-se que a absorção foi idêntica nos primeiros 30 dias, daí então a absorção foi mais elevada para a variedade Asgrow 40 aos 60 dias quando atingiu o valor máximo. Decresceu até os 80 dias, para crescer na última amostragem. Fato idêntico ocorreu com a variedade Okaw, no entanto, o decrescimo verificou-se entre 70 e 80 dias e o aumento no $90 .^{\circ}$ dia. O decrescimo na quantidade do nutriente nos órgãos vegetativos se deve talvez, a mobilização do nutriente para os órgãos reprodutores e a queda das folhas velhas. $\mathrm{O}$ acrescimo, a formação de folhas e vagens novas.

O valor máximo da absorção do cobre pela variedade Okaw, ocorreu na última amostragem, $51 \mathrm{~g} / \mathrm{ha}$, e comparando-se com 29 

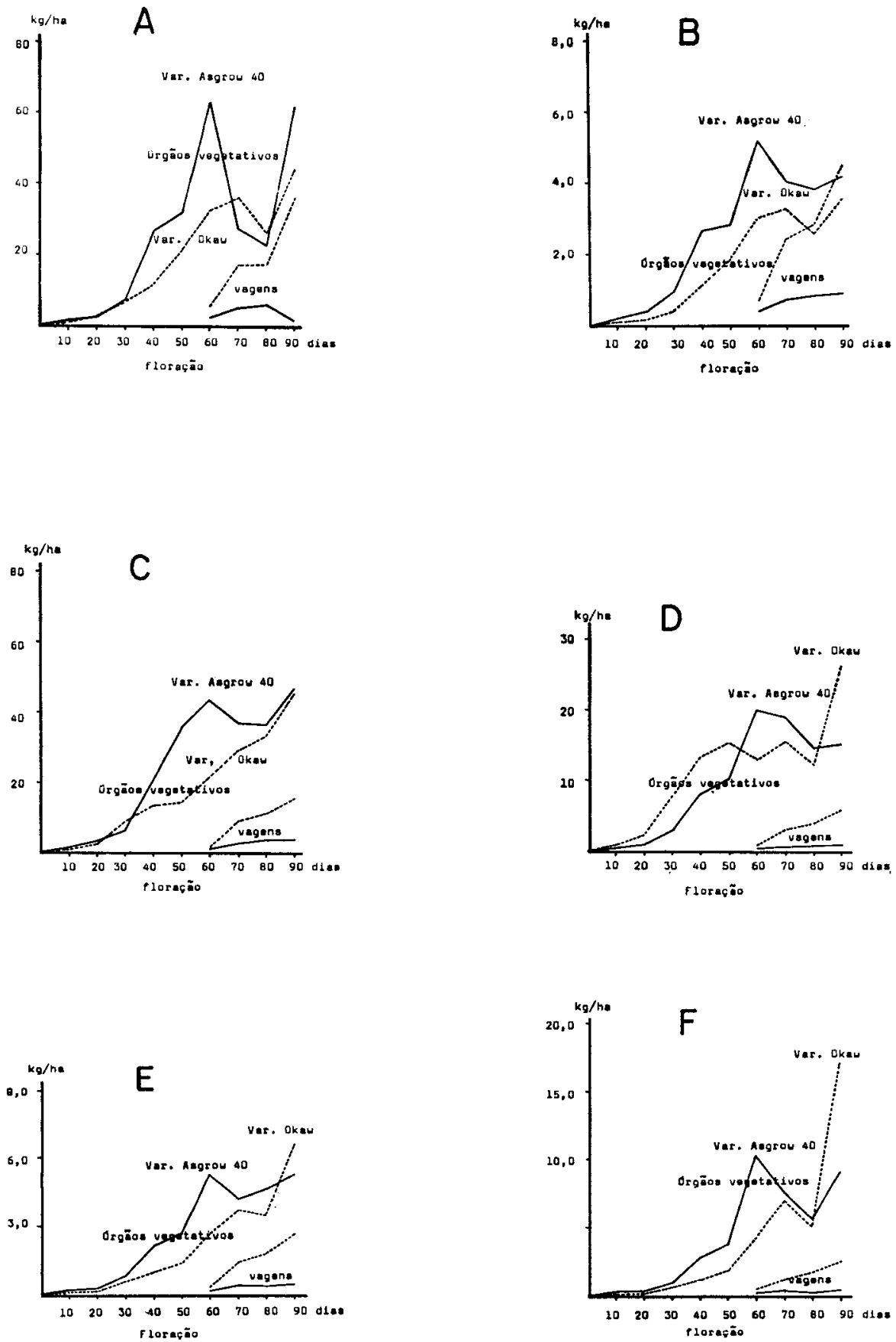

Fig. 3 - Extração dos macronutrientes em $\mathrm{Kg} / \mathrm{ha}$ em função do desenvolvimento da cultura - N (A); P (B); K (C); Ca (D); $\mathrm{Mg}(\mathrm{E}) ; \mathrm{S}$ (F). 
g/ha, valor observado aos 60 dias para a variedade Asgrow 40, acrescida das quantidades do nutriente encontradas nas vagens nas últimas amostragens, obtem-se $37 \mathrm{~g} / \mathrm{ha}$, valor que difere do primeiro de $14 \mathrm{~g} / \mathrm{ha}$, ou seja, $27 \%$ a favor da Okaw.

A absorção do ferro, pela variedade Asgrow 40, apresentou-se muito irregular. Ora era muito pronunciada, para depois cair quase verticalmente, e o valor máximo foi verificado aos 90 dias. A variedade Okaw, mostrou uma absorção contínua até o fim do ciclo.

O valor máximo observado para a variedade Asgrow 40 foi 250 $\mathrm{g} / \mathrm{ha}$, contra os $244 \mathrm{~g} / \mathrm{ha}$ absorvido pela Okaw, fornece uma diferença de $7 \mathrm{~g} /$ ha, ou seja, 2,8\% a favor da Asgrow 40. Figura 4 (C).

A absorção do manganês foi pequena até os 50 dias, quando cresceu bruscamente até o fim do ciclo para as duas variedades. 0 fato de grande acúmulo, superior ao ferro, se deve talvez às pulverizações periódicas feitas com Dithane M-45. Figura 4 (B).

O valor máximo observado para a variedade Asgrow 40, foi 278 $\mathrm{g} / \mathrm{ha}$ aos 90 dias, obtem-se um valor de $41 \mathrm{~g} / \mathrm{ha}$, ou seja, $15 \%$ da Asgrow 40.

O molibdênio, figura 4 (E), foi absorvido de modo distinto pelas duas variedades. Nos primeiros 20 dias, notou-se que a variedade Asgrow 40 foi mais efetiva em acumular o nutriente, que a partir de então cresceu verticalmente até os 70 dias, valor máximo absorvido, decrescendo também verticalmente no 80 dia, para voltar a crescer na última amostragem. A absorção do nutriente pela variedade Okaw, foi semelhante, no entanto o valor máximo foi observado no $90 .^{\circ}$ dia.

O valor máximo acumulado de molibdênio pela variedade Asgrow 40 foi $55 \mathrm{~g} / \mathrm{ha}$, e comparando-se com $4,9 \mathrm{~g} / \mathrm{ha}$, valor máximo absorvido pela variedade Okaw, observa-se que os dois valores praticamente não diferem entre si.

Os dados de absorção para zinco talvez não retrata os verdadeiros valores, devido às pulverizações periódicas efetuadas com Dithane M-45. Figura 4 (F).

Na variedade Asgrow 40, a absorção foi muito irregular durante todo ciclo, no entanto foi na última amostragem que atingiu o valor máximo. A variedade Okaw absorveu o nutriente continuamente até os 50 dias, quando a absorção cresceu assustadoramente, para atingir o valor máximo no $70 .^{\circ}$ dia.

A variedade Okaw, devido talvez a produção, apresentou maiores quantidades de todos os micronutrientes que a variedade Asgrow 40. 

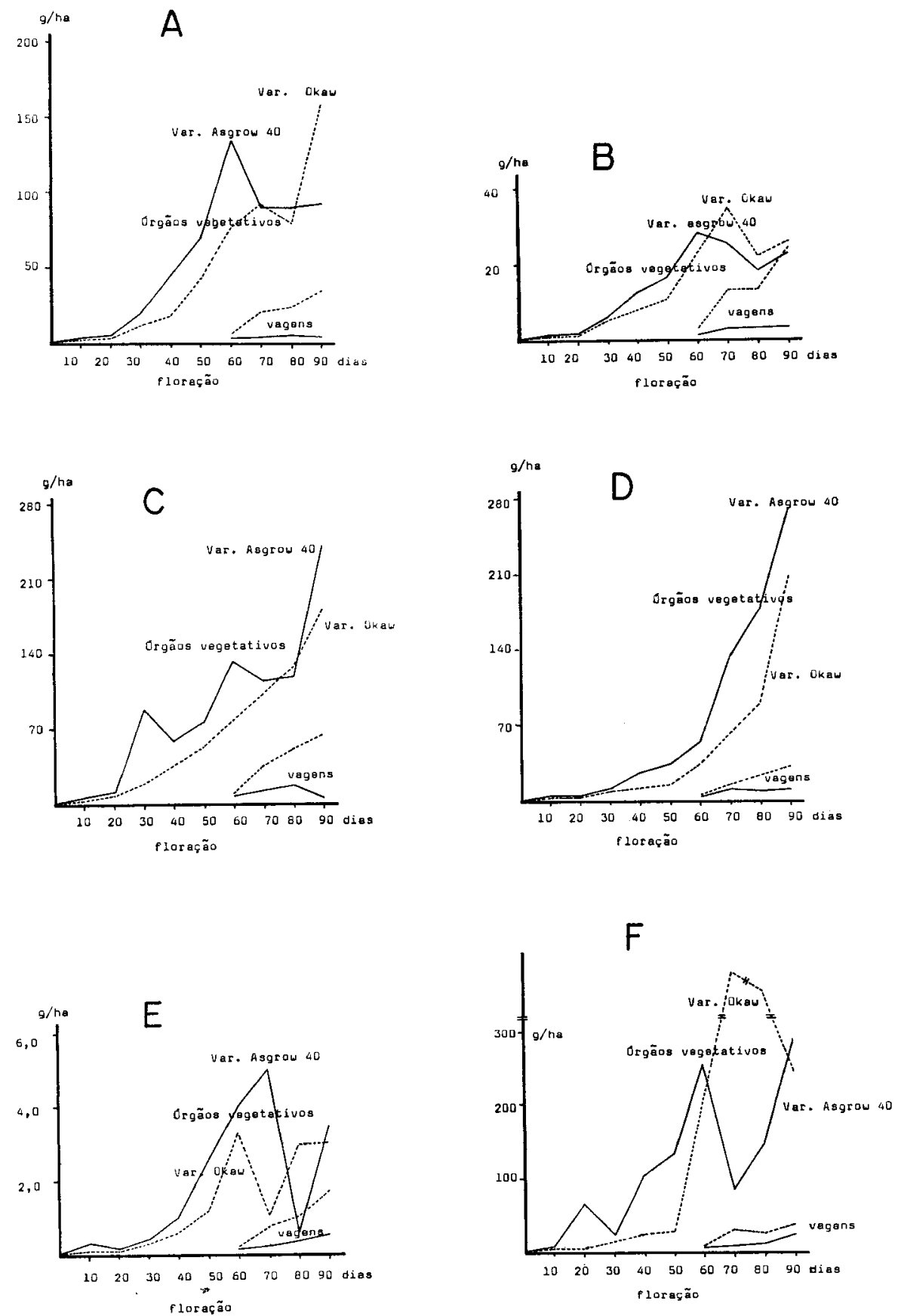

Figura 4 - Extração dos micronutrientes em $\mathrm{g} / \mathrm{ha}$ em função do desenvolvimento da cultura - B(A); Cu (B); Fe (C); Mn (D); Mo (E); Zn (F). 
A variedade Okaw foi mais capaz em absorver o nutriente, e apresentou aos 70 dias, $624 \mathrm{~g} / \mathrm{ha}$, contra $304 \mathrm{~g} / \mathrm{ha}$ absorvidos aos 90 dias pela variedade Asgrow 40, nos dá uma diferença de $320 \mathrm{~g} / \mathrm{ha}$, ou seja, $51 \%$.

As necessidades dos micronutrientes pelas duas variedades são também distintas, e além dissa, para determinados nutrientes, existem épocas preferenciais de absorção. Enquanto a variedade Okaw, de um modo geral, só no fim do ciclo é que as necessidades nutrionais eram satisfeitas, com a variedade Asgrow 40, tal fato ocorreu no meio do ciclo vegetativo.

A variedade Okaw parece ser mais exigente que a variedade Asgrow 40 nos seguintes micronutrientes: boro, cobre e zinco. As variedades foram similares na absorção do ferro, manganês e molibdênio.

Nas condições em que se desenvolveram o presente trabalho, pode-se considerar que obteve-se uma estimativa razoávl das quantidades dos macro e micronutrientes absorvidos pelas variedades Okaw e Asgrow $40 \mathrm{em}$ diversas idades fisiológicas. Assim, para as duas variedades, tomando-se sempre os valores máximos, verifica-se que estas duas variedades absorvem e exportam as quantidades de nutrientes contidos na tabela 9 .

A variedade Okaw apresentou os valores máximos na última amostragem, e as quantidades dos nutrientes exportados foram os encontrados nas vagens neste período.

Para a variedade Asgrow 40, no entanto, os valores máximos de extração foram obtidos somando-se às quantidades dos nutrientes nos órgãos vegetativos aos 60 dias, aos valores encontrados nas vagens nas quatro amostragens seguintes:

Observou-se que os nutrientes absorvidos em maiores quantidades para a variedade Okaw foram pela ordem decrescente: nitrogênio, potássio, cálcio, enxôfre, magnésio, fósforo, zinco, ferro, manganês, boro, cobre e molibdênio; para a variedade Asgrow 40 a sequiência foi a mesma, com excessão do ferro que foi sobrepujado pelo manganês.

As quantidades dos macronutrientes exportados por uma cultura de ervilha, observados por LAVALLEYE e STEPPE, (1966), o nitrogênio, o potássio, o fósforo e o magnésio apresentaram-se inferiores as encontrados no presente trabalho, no entanto, os valores para cálcio foram concordantes apenas na variedade Okaw.

Outro ponto discordante foi a sequiência dos nutrientes de maior 
TABELA 9 - Quantidades dos nutrientes extraidos e exportados em $\mathrm{kg} / \mathrm{ha}$ e em $\mathrm{g} / \mathrm{ha}$ nas vagens por uma cultura de ervilha.

\begin{tabular}{lccc|ccc}
\hline & \multicolumn{2}{c|}{ Variedade Okaw } & \multicolumn{3}{c}{ Variedade Asgrow } \\
\cline { 2 - 6 } & $\begin{array}{c}\text { Orgãos } \\
\text { vegeta- } \\
\text { tivos }\end{array}$ & Vagens & Total & $\begin{array}{c}\text { Orgãos } \\
\text { vegeta- } \\
\text { tivos }\end{array}$ & Vagens & Total \\
\hline Nitrogênio & $\mathrm{kg} / \mathrm{ha}$ & $\mathrm{kg} / \mathrm{ha}$ & $\mathrm{kg} / \mathrm{ha}$ & $\mathrm{kg} / \mathrm{ha}$ & $\mathrm{kg} / \mathrm{ha}$ & $\mathrm{kg} / \mathrm{ha}$ \\
Fósforo & 44 & 36 & 80 & 64 & 14 & 78 \\
Potássio & 3,7 & 4,3 & 8 & 5,2 & 2,7 & 7,9 \\
Cálcio & 46 & 16 & 62 & 47 & 3 & 50 \\
Magnésio & 26 & 6 & 32 & 20 & 2 & 21 \\
Enxôfre & 6,4 & 2,8 & 9,2 & 5,3 & 0,4 & 5,7 \\
Boro & 17 & 2 & 19 & 10 & 1 & 11 \\
Cobre & $\mathrm{g} / \mathrm{ha}$ & $\mathrm{g} / \mathrm{ha}$ & $\mathrm{g} / \mathrm{ha}$ & $\mathrm{g} / \mathrm{ha}$ & $\mathrm{g} / \mathrm{ha}$ & $\mathrm{g} / \mathrm{ha}$ \\
Ferro & 158 & 36 & 194 & 134 & 15 & 149 \\
Manganês & 26 & 25 & 51 & 28 & 9 & 37 \\
Molibdênio & 180 & 64 & 244 & 239 & 11 & 250 \\
Zinco & 205 & 32 & 237 & 268 & 9 & 278 \\
\hline & 32 & 1,7 & 4,9 & 5 & - & 5 \\
\hline
\end{tabular}

absorção, onde os autores afirmaram que a seqüência era potássio, nitrogênio, cálcio, fósforo e magnésio.

Observou-se pelos dados da tabela 9, que a variedade Okaw, apresentou característica de exportar maiores quantidades de nutrientes que a Asgrow 40.

\section{CONCLUSÕES}

O peso da matéria verde das duas variedades teve crescimento idêntico até os 60 dias, quando continuou crescendo para a variedade Okaw. O peso da matéria seca, no entanto, cresceu até a última amostragem nas duas variedades.

As variedades apresentaram épocas preferenciais distintas de 
absorção de nutrientes. A variedade Okaw apresentou a maior extração no fim do ciclo ( 90 dias), e a Asgrow 40 no meio do ciclo vegetativo (60 dias).

As quantidades dos nutrientes extraídos e exportados em $\mathrm{kg} / \mathrm{ha}$ para os macronutrientes $\mathrm{e} \mathrm{em} \mathrm{g} / \mathrm{ha}$ para os micronutrientes foram:

\begin{tabular}{|c|c|c|c|c|}
\hline \multirow{3}{*}{ Nutriente } & \multicolumn{2}{|c|}{ Extração } & \multicolumn{2}{|c|}{ Exportação } \\
\hline & \multicolumn{2}{|c|}{$($ caules $+\underset{\text { vagens })}{\text { folhas }}+$ flores +} & \multicolumn{2}{|c|}{ (vagens) } \\
\hline & $\begin{array}{c}\text { Var. Okaw } \\
\text { kg/ha }\end{array}$ & $\begin{array}{c}\text { Var. Asgrow } \\
40 \\
\mathrm{~kg} / \mathrm{ha}\end{array}$ & $\begin{array}{c}\text { Var. Okaw } \\
\text { kg/ha }\end{array}$ & $\begin{array}{c}\text { Var. Asgrow } \\
40 \\
\mathrm{~kg} / \mathrm{ha}\end{array}$ \\
\hline Nitrogênio & 80 & 78 & 36 & 14 \\
\hline Fósforo & 8 & 7,9 & 4,3 & 2,7 \\
\hline Potássio & 62 & 50 & 16 & 3 \\
\hline Cálcio & 32 & 21 & 6 & 2 \\
\hline Magnésio & 9,2 & 5,7 & 2,8 & 0,4 \\
\hline \multirow[t]{2}{*}{ Enxofre } & 19 & 11 & 2 & 1 \\
\hline & $\mathrm{g} / \mathrm{ha}$ & $\mathrm{g} / \mathrm{ha}$ & $\mathrm{g} / \mathrm{ha}$ & $\mathrm{g} / \mathrm{ha}$ \\
\hline Boro & 194 & 149 & 36 & 15 \\
\hline Cobre & 51 & 37 & 25 & 9 \\
\hline Ferro & 244 & 250 & 64 & 11 \\
\hline Manganês & 237 & 278 & 32 & 9 \\
\hline Molibdênio & 4,9 & 5,8 & 1,7 & 0,8 \\
\hline Zinco & 624 & 304 & 30 & 12 \\
\hline
\end{tabular}

A extração dos nutrientes pelas duas variedades foi semelhante.

A variedade Okaw apresentou maior exportação de nutrientes.

\section{SUMMARY}

MINERAL NUTRITION OF VEGETABLE CROPS.

XX - Absorption of macro and micronutrients by pea plants, varieties OKAW ans ASGROW 40.

Peas plants of the varieties Okaw and Asgrow 40 were cultivated incomplete nutrient solution. Periodically from 10 th day up to 90 
days. Height $(\mathrm{cm})$ dry wheigh matter (gr) of the plants were obtained at the different stage plants growing. Stalks, leaves husk+seeds, were analysed for $\mathrm{N}, \mathrm{P}, \mathrm{K}, \mathrm{Ca} \mathrm{Mg}, \mathrm{S}, \mathrm{B}, \mathrm{Cu}, \mathrm{Fe}, \mathrm{Mn}, \mathrm{Zn}$ and $\mathrm{Mo}$.

\section{Conclusions :}

1 - The variety Okaw presented a continous growth, expressed as "wet matter production" until the both day. For the variety Asgrow 40 the growth ceased around the 40th day;

2 - The capaty for nutrients extration were distinct between the varieties, for the variety Okaw around the 90th day for the variety Asgrow 40, around the 60th day;

3 - One ha of peas plants ( $\mathrm{kg} / \mathrm{ha}$ ) removed the following quanties in nutrients $\mathrm{kg}$.

\begin{tabular}{|c|c|c|c|c|}
\hline \multirow{3}{*}{ Nutrient } & \multicolumn{2}{|c|}{ Extraction } & \multicolumn{2}{|c|}{ Exported } \\
\hline & \multicolumn{2}{|c|}{$\begin{array}{c}\text { (stalks + leaves + flowers } \\
+ \text { "husk + seeds" }\end{array}$} & \multicolumn{2}{|c|}{ (husk + seeds) } \\
\hline & $\begin{array}{c}\text { Var. Okaw } \\
\text { kg/ha }\end{array}$ & $\begin{array}{c}\text { Var. Asgrow } \\
40 \\
\mathrm{~kg} / \mathrm{ha}\end{array}$ & $\begin{array}{c}\text { Var. Okaw } \\
\text { kg/ha }\end{array}$ & $\begin{array}{c}\text { Var. Asgrow } \\
40 \\
\mathrm{~kg} / \mathrm{ha}\end{array}$ \\
\hline $\mathbf{N}$ & 80 & 78 & 36 & 14 \\
\hline $\mathbf{P}$ & 8 & 7.9 & 4.3 & 2.7 \\
\hline $\mathrm{K}$ & 62 & 50 & 16 & 3 \\
\hline $\mathrm{Ca}$ & 32 & 21 & 6 & 2 \\
\hline $\mathrm{Mg}$ & 9.2 & 5.7 & 2.8 & 0.4 \\
\hline \multirow[t]{2}{*}{$\mathrm{S}$} & 19 & 11 & 2 & 1 \\
\hline & gr./ha & gr./ha & gr./ha & gr./ha \\
\hline B & 194 & 149 & 36 & 15 \\
\hline $\mathrm{Cu}$ & 51 & 37 & 25 & 9 \\
\hline $\mathrm{Fe}$ & 244 & 250 & 64 & 11 \\
\hline $\mathrm{Mn}$ & 237 & 278 & 32 & 9 \\
\hline Mo & 4.9 & 5.8 & 1.7 & 0.8 \\
\hline $\mathrm{Zn}$ & 624 & 304 & 30 & 12 \\
\hline
\end{tabular}


4 - the extraction of nutrients were similars in both varieties;

5 - the exportations of nutrients were higher in the variety Okaw, than in the variety Asgrow 40.

\section{LITERATURA CITADA}

BERNARDI, J. B. Instruções práticas: Cultura da ervilha. O Agrônomico. I.A.C., Campinas, São Paulo, 13(9-10):11-14, 1961.

CHAPMAM, H. D. e PRATT, P. F. Methods of analysis for soils plant and waters: Total sulfur in plants. California, 1961.

JOHNSON, C. M., A. ULRICH 1959 II. Analytical methods for use in plant analysis. Calif. Agr. Sta Exp. Bull 766. Berkelay, California, U.S.A.

LAVALLEYE, M. e STEPPE, H. H. Effects of potash on pea growth and quality. Simposium Potassium. Berne, Switzerland, 8:235-248, 1966.

LOTT, W. L., NERY, J. P., GALLO, J. R. e MEDSCALF, J. C. A técnica da análise foliar aplicada ao cafeeiro. Boletim. I. A.C., Campinas, São Paulo, $79,1956$.

MACLEAN, K. S. e BYERS, D. L. Nutrient content of field grown peas. Can. J. Plant Sci. New Scetia, Canadá, 48:155-156, 1968.

MALAVOLTA, E. Práticas de química orgânica e biológica. Centro Acadêmico "Luiz de Queiroz", Piracicaba, São Paulo. 1957.

McHARGUE, J. S. Iron and manganese content of certain species of seeds. Jour. Agr. Research. Washington, D.C. 23(6):395-399, 1923.

OLIVEIRA, H. A., MORAES, J. F. V., PILCZER, M. M., KALCKAMNN, R. E. e SILVA, J. G. C. Efeitos da aplicação de nitrogênio, fósforo, potássio e calcário na cultura da ervilha (Pisum sativum, L.) em Rosário do Sul, Rio Grande do Sul. Pesquisa Agropecuária Brasileira. Ministério da Agricultura, Rio de Janeiro, 3:243-253, 1968.

PERKIN-ELMER CORP. Analytical methods for atomic absorption aspect photometry. Perkin-Elmer Corp. Connecticult, U.S.A. - 1966.

SARRUGE, J. R. Coleta e preparo das amostras vegetais para análise. Curso Pós-Graduado de Solos e Nutrição de Plantas, Piracicaba, São Paulo, 1971 (mimeo).

TREMBLAY, F. T. e BAUR, K. E. Plant analysis: A methods of determining the phosphorus requirements of peas. Agron. J. Madison, U.S.A. 44:614-618, 1952. 
